\title{
Compassion Satisfaction and Fatigue, Emotional Dissonance, and Burnout in Therapists in Rehabilitation Hospitals
}

\author{
Hee Jin Kim¹, Jung Hee Ha ${ }^{1}$, Juliet Jue ${ }^{2}$ \\ ${ }^{1}$ Graduate School of Counseling Psychology, Hanyang University, Seoul, Republic of Korea \\ ${ }^{2}$ Department of Art Therapy, Hanyang Cyber University, Seoul, Republic of Korea \\ Email: ^hajung366@hanyang.ac.kr
}

How to cite this paper: Kim, H. J., Ha, J. H., \& Jue, J. (2020). Compassion Satisfaction and Fatigue, Emotional Dissonance, and Burnout in Therapists in Rehabilitation Hospitals. Psychology, 11, 190-203. https://doi.org/10.4236/psych.2020.111013

Received: December 24, 2019

Accepted: January 14, 2020

Published: January 17, 2020

Copyright ( 2020 by author(s) and Scientific Research Publishing Inc. This work is licensed under the Creative Commons Attribution International License (CC BY 4.0).

http://creativecommons.org/licenses/by/4.0/ (c) (i) Open Access

\begin{abstract}
This study was an examination of the relationship between emotional dissonance and burnout among therapists working in rehabilitation hospitals. The mediating effects of compassion satisfaction and compassion fatigue were verified through structural equation modeling. The participants were 204 therapists working at rehabilitation hospitals located in a metropolitan area, and they completed the Emotional Dissonance Scale, the Maslach Burnout Inventory, and the Professional Quality of Life Scale. The results are as follows. First, emotional dissonance, compassion satisfaction, and compassion fatigue had significant correlations with burnout. Second, mediating effects of compassion satisfaction/fatigue were found in the relationship between emotional dissonance and burnout. Consequently, emotional dissonance had both direct and indirect effects on burnout. Lastly, this study's implications, limitations and suggestions for future study are presented.
\end{abstract}

\section{Keywords}

Rehabilitation Therapists, Emotional Dissonance, Compassion Satisfaction, Compassion Fatigue, Burnout

\section{Introduction}

Rehabilitation refers to all therapeutic interventions performed in an effort to improve and maintain optimal sensory, physical, cognitive, psychological and social performance in persons with disabilities; rehabilitation encompasses the full range of treatment to recover patients' quality of life (QoL). Professionals including physical therapists, occupational therapists, psychotherapists, and speech 
therapists who provide professional services in the field of rehabilitation are essential to improving QoL for people with disabilities. However, therapists in rehabilitation hospitals often experience burnout (Lloyd \& King, 2001), especially when a patient's recovery is slow and the patient or caregivers feel stress about the process (Kim, 1987). This is especially true considering that the main purpose of rehabilitation hospitals is continuous and intensive rehabilitation of patients after the acute phase of injury (Korea Health Industry Development Institute, 2005).

Burnout is defined as emotional depletion and cynicism in helping professionals who work face to face with clients, and helping professionals are prone to experience burnout (Delia \& Patrick, 1996). Researchers have described how therapists who are experiencing burnout can experience gradual deterioration in their therapeutic skills and abilities and how burnout can lead to potential incompetence (Cherniss, 1980; Seo, 2012; Suh \& Kim, 2002; Yoo \& Park, 2002); burnout in this way prevents therapists from effectively using their expertise in providing services, and there have been reports of burnouts in nurses (Ahn, Yea, \& Yeum, 2011), physical therapists (Kim, 2014), and occupational therapists (Lee \& Jung, 2016).

Rehabilitation therapists who work in hospitals have high job stress (Kim, 2014). They must provide therapeutic services, but they must also do emotional labor when they have to ignore or control their feelings. In this process, emotional dissonance occurs in rehabilitation therapists who have experienced burnout.

Emotional dissonance is defined as a discrepancy in emotions when there is a conflict between personal feelings and norms that require specific attitudes (Brotheridge, 2001). Because many medical institutions place customer satisfaction first, customers now expect and demand continuously increasing levels of service from medical professionals; consequently, emotional dissonance is inevitable for emotional laborers in hospitals (Kim \& Kim, 2013). Prior research has shown that emotional dissonance causes fatigue that impedes performance, deepens burnout, and negatively affects job performance (Dormann \& Kaiser, 2002). The greater the emotional dissonance a person experiences, the more likely the person will experience a false ego, considering him- or herself as hypocritical, leading to psychological maladjustment (Ashforch \& Humphrey, 1993). Emotional dissonance causes a number of negative effects including tension, stress, burnout, alienation from true feelings, lower self-esteem, and work dissatisfaction (Heuven \& Bakker, 2003; Mann, 2004), and emotional dissonance is also closely related to burnout (Kirk, Koeske, \& Koeske, 1993).

Considering the factors that affect emotional dissonance and burnout, we proposed examining compassion satisfaction and compassion fatigue. Compassion satisfaction refers to the joyful feelings that result from having the ability to help others (Figley \& Stamm, 1996) and the experience of contentment in the course of helping others (Stamm, 2010). Collins \& Long (2003) described com- 
passion satisfaction as a defensive factor against compassion fatigue, a buffer against traumatic experience. Compassion fatigue, on the other hand, results from stress in the course of work, and it has a mental and emotional impact. It is similar to burnout but unique in being found only in helping professionals who work with trauma victims (Robins, Meltzer, \& Zelikovsky, 2009). Compassion fatigue is the result of emotional exhaustion from helping others (Sabo, 2008), and it occurs more often in situations where constant compassion is required (Fetter, 2012); it can cause anger, fatigue, headache, gastrointestinal disorders, high blood pressure, weight changes, and sleep disorders and weaken the immune system (Figley, 2012).

Previous studies with helping professionals showed that emergency room nurses who performed frequent emotional labor experienced more emotional dissonance (Yoon, 2003), and greater emotional dissonance reduces compassion satisfaction and increases compassion fatigue (Jeong, 2016). Furthermore, nurses' high compassion fatigue increased burnout (Kim, 2011; Lee, 2015; Lee \& Yom, 2013), and the same result was obtained in a study of firefighters (Kim, 2019). Compassion satisfaction and compassion fatigue are related to burnout: Stamm (2010) observed that the former decreases the possibility of burnout while the latter increases possibilities of burnout and secondary traumatic stress. In addition, high compassion satisfaction reduces burnout due to work-related stress (Conrad \& Kellar-Guenther, 2006; Robertson \& Gow, 2011; Stamm, 2002), acts as a protective mechanism against secondary traumatic stress, and maintains mental well-being (Collins \& Long, 2003).

Based on these findings, we aimed with this study to investigate the relationships between emotional dissonance, compassion satisfaction, compassion fatigue, and burnout in therapists in various fields in rehabilitation hospitals. Based on findings that compassion satisfaction is a source of strength for continuing work in high-stress jobs while compassion fatigue increases burnout (Jeon \& Ha, 2012; Kim, 2011), we assumed that compassion satisfaction and compassion fatigue would have a mediating effect on the relationship between emotional dissonance and burnout. Few investigators have examined the paths between emotional dissonance, compassion satisfaction, compassion fatigue, and burnout at the same time. Thus, the aim of this study was to provide basic data for reducing burnout in rehabilitation therapists and preparing necessary preventive interventions for them.

As presented in Figure 1, we set up a research model that included direct and indirect relationships between emotional dissonance and burnout. A competition model does not assume a direct relationship between the two, and we compared the two models to verify the following research questions: 1) What is the relationship between emotional dissonance and burnout in therapists working in rehabilitation hospitals? 2) Do compassion satisfaction and compassion fatigue have a mediating effect in the relationship between emotional dissonance and burnout in therapists working in rehabilitation hospitals? 


\section{Method}

\subsection{Participants}

This study entailed a survey of 204 therapists working in two rehabilitation hospitals located in a metropolitan area. We excluded two questionnaires for incomplete response data, leaving 202 questionnaires for the data analysis. The participants' mean age was $28.79 \pm 4.85$ years and the other demographic characteristics of the participants were presented in Table 1.

\subsection{Procedure}

We conducted this study after receiving research approval from the Seoul Rehabilitation Hospital Institutional Review Board (IRB No. SRH2018R-04); the distributed surveys were either on paper or online. We provided the following

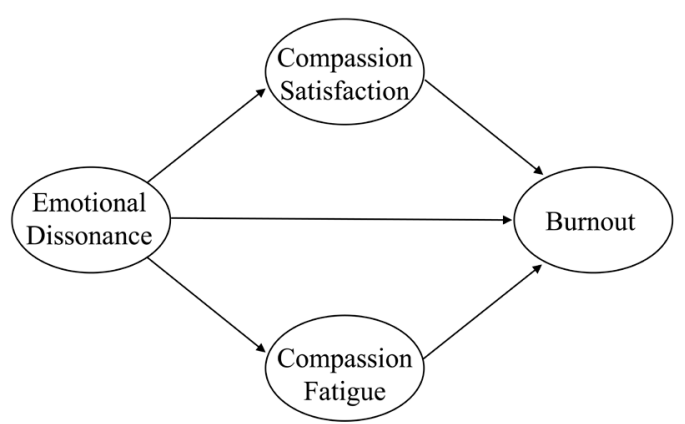

(a)

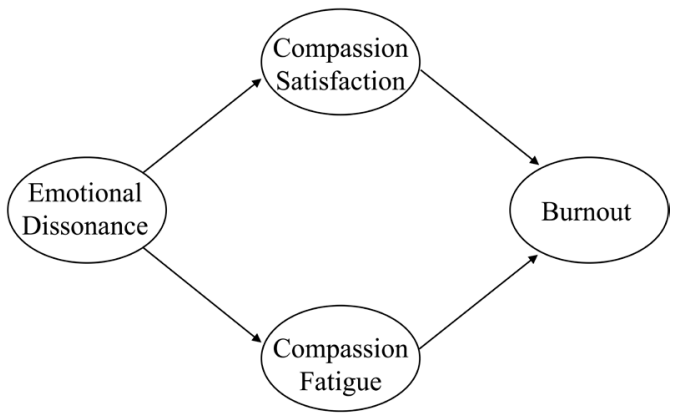

(b)

Figure 1. Two models in this study. (a) Research model; (b) Competition model.

Table 1. Participants' general characteristics $(\mathrm{N}=202)$.

\begin{tabular}{|c|c|c|c|}
\hline & Variable & Frequency & Percentage \\
\hline \multirow[t]{2}{*}{ Sex } & Male & 81 & 40.1 \\
\hline & Female & 121 & 59.9 \\
\hline \multirow[t]{3}{*}{ Education level } & Vocational college graduate & 34 & 16.8 \\
\hline & College graduate & 138 & 68.3 \\
\hline & Master's degree holder & 30 & 14.9 \\
\hline \multirow[t]{5}{*}{ Total work experience } & $<1$ year & 27 & 13.3 \\
\hline & $1-5$ years & 70 & 34.7 \\
\hline & $5-10$ years & 80 & 39.6 \\
\hline & $10-15$ years & 15 & 7.4 \\
\hline & $>15$ years & 10 & 5.0 \\
\hline \multirow[t]{5}{*}{ Specific job } & Physical therapist & 102 & 50.5 \\
\hline & Occupational therapist & 77 & 38.1 \\
\hline & Speech therapist & 12 & 5.9 \\
\hline & Psychotherapist & 10 & 5.0 \\
\hline & others & 1 & 0.5 \\
\hline
\end{tabular}


information on the first page of the questionnaire: the purpose of the study and the fact that all questionnaires were anonymous, the survey could be discontinued at any time if participants wanted to stop, and the collected data were used for research purposes only. After participants signed a consent form, they began responding. The questionnaire was in the order of the Emotional Dissonance Scale, the Maslach Burnout Inventory, and the Professional Quality of Life Scale version 5 . When they completed the surveys, participants received small gifts in appreciation of their time.

\subsection{Measures}

- Emotional Dissonance Scale. Park (2008) developed the Emotional Dissonance Scale to fit hospital employees based on Kruml \& Geddes' (2000) Dimensions of Emotional Labor. The scale is composed of four items rated on a seven-point Likert scale; one sample scale item is "Sometimes it is hard because I show feelings to patients that do not match my real feelings," and higher scores indicate greater emotional dissonance. Park reported a Cronbach's $\alpha$ of 0.78 , while it was 0.86 in this study. Because this was a singlefactor scale, we randomly assigned the items to construct two parcels for analysis.

- Maslach Burnout Inventory. Maslach \& Jackson (1981) developed the Maslach Burnout Inventory (MBI), and it was translated and modified by Lee (2011). The MBI consists of three sub-factors: emotional exhaustion, depersonalization, and decrease in personal accomplishment. The emotional exhaustion subscale measures psychological overload and feelings of fatigue at work. The depersonalization subscale assesses one's degree of dehumanization, that is, treating service recipients in a cold way. The decrease in personal accomplishment subscale measures feelings of incompetence and unsuccessful achievements in work with people. The MBI is composed of nine items for emotional exhaustion, five for depersonalization, and eight for decrease in personal accomplishment, for a total of 22 items, all rated on five-point Likert scales ( $1=$ strongly disagree, $5=$ strongly agree); the higher the score, the higher the burnout. Lee found a Cronbach's a of 0.80 for the MBI, and the alpha was 0.89 in this study.

- Professional Quality of Life Scale. We employed the Professional Quality of Life Scale version 5 (ProQOL-5) to assess compassion satisfaction and compassion fatigue in the participants. The ProQOL-5 was developed by Stamm (2009) and is composed of three subscales measuring compassion satisfaction, burnout, and compassion fatigue. We used the compassion satisfaction and compassion fatigue subscales; each has ten items rated on a five-point Likert scale. For the compassion fatigue subscale, we used eight items after excluding two items that did not belong to the factor; the higher the score, the stronger the construct. Stamm reported that the Cronbach's a was 0.88 for compassion satisfaction and 0.81 for compassion fatigue. In this study, we 
found that Cronbach's $\alpha$ was 0.89 for compassion satisfaction and 0.66 for compassion fatigue. Because this was a single-factor scale, we randomly assigned the items to construct two parcels for analysis.

\subsection{Data Analysis}

We analyzed the data using IBM SPSS 24.0 and AMOS 21.0. First, we identified the demographic characteristics of the study participants and established the reliability of the measurement tools; then we calculated descriptive statistics and conducted correlation analyses. We checked skewness and kurtosis to judge normality, which is the basic assumption of a structural equation model.

Second, we performed confirmatory factor analysis to validate the model, checking the fit and factor load of the measurement model. We used the absolute fit index RMSEA and the central fit index TLI and CFI to test the measurement model's goodness of fit (Hong, 2000). The Tucker-Lewis and comparative fit indices are considered to indicate high model fit at 0.9 and above; for RMSEA, below 0.05 is very good, below 0.08 is good, and below 0.10 is moderate (Woo, 2012).

Third, we analyzed the research model using AMOS 21, using RMSEA, TLI, and CFI to verify the research model's fit (Hong, 2000). Finally, we examined the indirect effect through the path coefficient of the final model and performed bootstrapping to verify the mediating effect.

\section{Results}

\subsection{Descriptive Statistics and Correlations between Variables}

We analyzed the correlations between each variable, and the results are shown in Table 2 and Table 3. We found that emotional dissonance had a significant negative correlation with compassion satisfaction and a significant positive correlation with compassion fatigue. In addition, emotional dissonance had a significant positive correlation with burnout. Compassion satisfaction and fatigue were, respectively, negatively and positively correlated with burnout. We examined the skewness and kurtosis of our data and found that the largest absolute skewness was 0.45 and the largest absolute kurtosis was 0.46 . These results satisfied the normal distribution assumption.

\subsection{Verifying the Measurement Model}

Before we verified the research model, we conducted confirmatory factor analysis to validate the measurement variables. The factor loadings of the measurement variables ranged from 0.55 to 0.96 , which were estimated as a significant path. Specifically, the loadings for emotional dissonance were 0.84 and 0.95 , and those for compassion satisfaction were 0.96 and 0.89 . The compassion fatigue factor loadings were 0.80 and 0.66 , and the burnout loadings were $0.65,0.73$, and 0.55 . We judged the measurement model to be appropriate.

Next, we examined the overall fit of the measurement model. We found the 
Table 2. Correlations between observed variables, means, standard deviations, skewness, and kurtosis $(\mathrm{N}=202)$.

\begin{tabular}{|c|c|c|c|c|c|c|c|c|c|c|}
\hline \multicolumn{2}{|c|}{ Variable } & \multirow{2}{*}{$\begin{array}{l}1 \\
-\end{array}$} & \multirow[t]{2}{*}{2} & \multirow[t]{2}{*}{3} & \multirow[t]{2}{*}{4} & \multirow[t]{2}{*}{5} & \multirow[t]{2}{*}{6} & \multirow[t]{2}{*}{7} & \multirow[t]{2}{*}{8} & \multirow[t]{2}{*}{9} \\
\hline ED & 1. ED1 & & & & & & & & & \\
\hline & 2. ED2 & $0.79^{\star \star}$ & - & & & & & & & \\
\hline \multirow[t]{2}{*}{ CS } & 3. CS1 & $-0.21^{\star *}$ & $-0.27^{\star *}$ & - & & & & & & \\
\hline & 4. CS2 & $-0.19^{* *}$ & $-0.21^{\star *}$ & $0.85^{* *}$ & - & & & & & \\
\hline \multirow[t]{2}{*}{$\mathrm{CF}$} & 5. CF1 & $0.29^{* \star}$ & $0.30^{\star \star}$ & $-0.17^{*}$ & $0.15^{\star}$ & - & & & & \\
\hline & 6. CF2 & $0.25^{* *}$ & $0.19^{\star *}$ & -0.06 & -0.06 & $0.53^{\star *}$ & - & & & \\
\hline \multirow[t]{3}{*}{ B } & 7. DP & $0.35^{* *}$ & $0.41^{\star *}$ & $-0.36^{* *}$ & $-0.32^{\star *}$ & $0.44^{* *}$ & $0.31^{* *}$ & - & & \\
\hline & 8. $\mathrm{EE}$ & $0.46^{* *}$ & $0.53^{* *}$ & $-0.43^{* *}$ & $-0.39^{* *}$ & $0.41^{* *}$ & $0.36^{* *}$ & $0.53^{* *}$ & - & \\
\hline & 9. PA & $0.21^{\star *}$ & $0.23^{* *}$ & $-0.57^{\star *}$ & $-0.56^{* *}$ & $0.22^{* *}$ & 0.13 & $0.36^{* *}$ & $0.32^{* *}$ & - \\
\hline \multicolumn{2}{|c|}{ Mean } & 3.77 & 4.09 & 3.48 & 3.55 & 2.50 & 2.43 & 1.93 & 2.78 & 2.44 \\
\hline \multicolumn{2}{|r|}{ S.D. } & 1.21 & 1.27 & 0.56 & 0.57 & 0.60 & 0.57 & 0.61 & 0.68 & 0.42 \\
\hline \multicolumn{2}{|c|}{ Skewness } & -0.31 & -0.38 & -0.03 & -0.08 & -0.03 & 0.18 & 0.45 & 0.36 & 0.41 \\
\hline \multicolumn{2}{|c|}{ Kurtosis } & -0.46 & -0.05 & -0.21 & -0.26 & 0.04 & 0.17 & 0.21 & -0.04 & 0.31 \\
\hline
\end{tabular}

Note. ED: Emotional Dissonance, CS: Compassion Satisfaction, CF: Compassion Fatigue, B: Burnout, DP: Depersonalization, EE: Emotional Exhaustion, PA: Personal accomplishment, ${ }^{*} p<0.05,{ }^{\star *} p<0.01$.

Table 3. Correlations between potential variables $(\mathrm{N}=202)$.

\begin{tabular}{lcccc}
\hline \multicolumn{1}{c}{ Variable } & 1 & 2 & 3 & 4 \\
\hline 1. Emotional Dissonance & - & & & \\
2. Compassion Satisfaction & $-0.24^{* *}$ & - & & \\
3. Compassion Fatigue & $0.31^{* *}$ & -0.13 & - & \\
4. Burnout & $0.53^{* *}$ & $-0.57^{* *}$ & $0.47^{* *}$ & - \\
\hline
\end{tabular}

${ }^{* *} p<0.01$.

following results: $\chi^{2}(\mathrm{~N}=202, \mathrm{df}=21)=55.91(p<0.001), \mathrm{CFI}=0.96, \mathrm{TLI}=$ 0.93 , and RMSEA $=0.09$. Therefore, the overall fit of the measurement model we used in this study was appropriate.

\subsection{Verifying the Structural Model}

We set a research model and a competition model as follows: The research model assumed a partial mediation effect of compassion satisfaction/fatigue in the relationship between emotional dissonance and burnout, while the competition model assumed a complete mediation effect that did not include a direct path between emotional dissonance and burnout. The results of confirming the goodness of fit are presented in Table 4; the TLI and RMSEA of the competitive models were not as good as those of the research model. In addition, the difference between $\chi^{2}$ of the competition model and that of the research model was 19.38, which was larger than the threshold of 3.84 for the difference of degrees of freedom 1 , indicating that the $\chi^{2}$ difference was significant. A partial mediation model 
is chosen when the $\chi^{2}$ difference is significant (Hong, 2000), and therefore, for this study, we chose the research model as the final model.

Next, we verified the path coefficients and significance of the final model. As shown in Figure 2 and Table 5, the path coefficients among all variables in the established pathways were statistically significant (C.R. $\geq 1.96$ ). Specifically, emotional dissonance positively affected burnout $(\beta=0.35, p<0.001)$ and compassion fatigue $(\beta=0.39, p<0.001)$ and negatively affected compassion satisfaction $(\beta=-0.29, p<0.001)$. Compassion satisfaction negatively affected burnout ( $\beta=-0.52, p<0.001)$, while compassion fatigue had a positive effect on burnout $(\beta=0.48, p<0.001)$.

\subsection{Verifying the Mediating Effect}

We conducted bootstrap analysis to verify the mediating effects of compassion

Table 4. The fit of research model and of competition model.

\begin{tabular}{ccccccc}
\hline & $\chi^{2}$ & df & $p$ & CFI & TLI & RMSEA (90\% CI) \\
\hline Research model & 56.68 & 22 & 0.00 & 0.96 & 0.93 & $0.09(0.06 \sim 0.12)$ \\
Competition model & 76.06 & 23 & 0.00 & 0.94 & 0.90 & $0.11(0.08 \sim 0.13)$ \\
\hline
\end{tabular}

Note. CI: Confidence Interval.

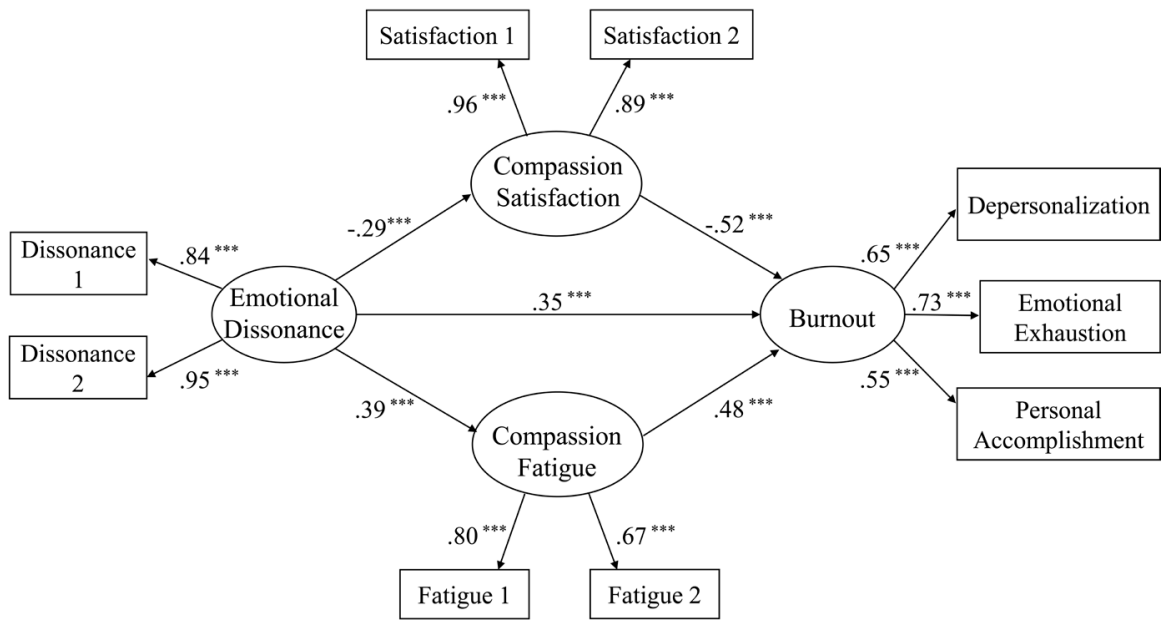

Figure 2. The final model's path; all estimates are standardized coefficients.

Table 5. The results of path coefficients.

\begin{tabular}{ccccc}
\hline Route & B & $\beta$ & S.E. & C.R. \\
\hline $\mathrm{ED} \rightarrow \mathrm{CS}$ & -0.15 & $-0.29^{* * *}$ & 0.04 & -3.80 \\
$\mathrm{ED} \rightarrow \mathrm{CF}$ & 0.18 & $0.39^{* * *}$ & 0.04 & 4.48 \\
$\mathrm{CS} \rightarrow$ Burnout & -0.38 & $-0.52^{* * *}$ & 0.06 & -6.80 \\
$\mathrm{CF} \rightarrow$ Burnout & 0.40 & $0.48^{* * *}$ & 0.08 & 4.77 \\
$\mathrm{ED} \rightarrow$ Burnout & 0.13 & $0.35^{* * *}$ & 0.03 & 4.47 \\
\hline
\end{tabular}

Note. ED: Emotional Dissonance, CS: Compassion Satisfaction, CF: Compassion Fatigue, B: unstandardized coefficients, $\beta$ : standardized coefficients, S.E.: standard error, C.R.: critical ratio, ${ }^{* *} p<0.001$. 
satisfaction/fatigue in the relationship between emotional dissonance and burnout. The indirect effects and confidence intervals of the mediation model are presented in Table 6. Interpreting bootstrap results assumes statistical significance when there is no 0 between the lower and upper limits (Preacher \& Hayes, 2008). The results showed that the indirect effects of compassion satisfaction and compassion fatigue were statistically significant in the relationship between emotional dissonance and burnout; emotional dissonance influenced burnout by mediating compassion satisfaction and compassion fatigue.

The results obtained in this study are summarized as follows. First, the three predictors of burnout-emotional dissonance, compassion satisfaction, and compassion fatigue-had significant correlations with burnout. Second, mediating effects of compassion satisfaction/fatigue were found in the relationship between emotional dissonance and burnout; in other words, emotional dissonance affected compassion satisfaction/fatigue, which in turn affected burnout. Consequently, emotional dissonance had both direct and indirect effects on burnout.

\section{Conclusion}

For this study, we examined the relationship between emotional dissonance and burnout in therapists working in rehabilitation hospitals, and we explored the mediating effects of compassion satisfaction and compassion fatigue in the process. The conclusion and their implications are as follows.

First, all predictors of burnout we used in this study showed significant positive and negative correlations with burnout. Emotional dissonance had a strong positive correlation, which supported the previous findings on the relationship between emotional dissonance and burnout (Kirk et al., 1993; Lewig \& Dollard, 2003; Morris \& Feldman, 1996; Suh \& Kim, 2002). In the previous studies, the study subjects were case managers, call center workers, and psychotherapists. Therefore, we expanded the scope of subjects, and we confirmed that therapists in rehabilitation hospitals also experience emotional dissonance and eventually burnout when they suppress or disguise their actual feelings in their professional roles.

The reduction in burnout with increased compassion satisfaction is in line with findings from previous studies (Collins \& Long, 2003; Jun, 2013; Kim, 2013; Slocum-Gori, 2011; Stamm, 2002; Yang, 2013; Yom \& Kim, 2012). Previous researchers obtained their results from nurses and hospice and mental health

Table 6. Verification results of mediating effect $(\mathrm{N}=202)$.

\begin{tabular}{cccc}
\hline \multirow{2}{*}{ Path } & Indirect effects & \multicolumn{2}{c}{$95 \% \mathrm{CI}$} \\
\cline { 3 - 4 } & & Lower & Upper \\
\hline $\mathrm{ED} \rightarrow \mathrm{CS} \rightarrow$ Burnout & $0.08^{* * *}$ & 0.02 & 0.19 \\
$\mathrm{ED} \rightarrow \mathrm{CF} \rightarrow$ Burnout & $0.15^{* * *}$ & 0.05 & 0.30 \\
\hline
\end{tabular}

Note. CI: Confidence Interval, ED: Emotional Dissonance, CS: Compassion Satisfaction, CF: Compassion Fatigue, ${ }^{* * *} p<0.001$. 
care workers, and we have added findings for rehabilitation therapists. Consistently across all of these groups, compassion satisfaction reduced the risk of burnout. Similarly, increased burnout that accompanied compassion fatigue was consistent across subjects, and the findings in this study supported that conclusion.

Second, in the relationship between therapists' emotional dissonance and burnout, we observed partial mediating effects of compassion satisfaction and compassion fatigue. This study's important contribution lies in how our findings integrate with the results of previous studies. Specifically, previous researchers examined the relationships among individual constructs: In one study, emotional dissonance had a statistically significant effect on compassion satisfaction and compassion fatigue (Jeong, 2016). Other studies have shown that compassion satisfaction and compassion fatigue have a significant effect on burnout (Friedman, 2002; Kim, 2011; Shin, 2007). With this study, we could observe both direct and indirect effects by examining these relationships together.

The implications of this study are as follows. First, we identified factors that affect burnout specifically among therapists working in rehabilitation hospitals, an understudied population. The findings indicate that the greater their emotional dissonance, the more rehabilitation therapists experience burnout. Most service employment suggests rules for expressing feelings that make the other person feel better, including kindness and patience (Park \& Shin, 2011; Seffrin, 2002), and rehabilitation hospitals are no exception; this explains why hospital therapists are more likely to experience emotional dissonance. However, considering the results of this study, finding ways to reduce emotional dissonance and preparing countermeasures are necessary for reducing rehabilitation therapist burnout.

Second, this study is meaningful in that we examined the relationships between emotional dissonance, compassion satisfaction, compassion fatigue, and burnout all together. For this study, we investigated the influences of compassion satisfaction and compassion fatigue as the mediators on the relationship between emotional dissonance and burnout. Researchers have examined these relationships individually, but few have looked at them together. In addition, it is meaningful that we could integrate the results of previous studies and model the associations between the predictors of burnout.

Third, we detailed how rehabilitation therapists' emotional dissonance led to burnout by discovering the mediating effects of compassion satisfaction and compassion fatigue in the relationship between emotional dissonance and burnout. Unresolved compassion fatigue eventually leads to burnout, and burnout causes physical, mental, and emotional exhaustion. It reduces therapists' quality of care and professionalism and increases turnover potential, which affects hospital management. Therefore, efforts to reduce burnout among rehabilitation therapists are necessary. Because compassion fatigue can be prevented and treated (Lombardo \& Eyle, 2011), effective interventions to minimize it in therapists need to be developed. 
The limitations of this study are as follows. First, we examined therapists in rehabilitation hospitals in Korea, so there is limited generalizability of our results to all rehabilitation therapists. Second, we did not cover all possible variables that could affect the burnout. Therefore, other factors may affect burnout in rehabilitation therapists in addition to the factors we examined.

There might be suggestions for future studies. First, it is important to reduce compassion fatigue to reduce burnout in therapists, and qualitative research will be needed for in-depth analyses of the compassion fatigue experienced by therapists. Second, based on the findings from this study, interventions to reduce burnout should be developed and studied, and further research will be needed to verify their effectiveness. We hope that these findings and those from future studies will contribute to the well-being of the therapists in rehabilitation hospitals.

\section{Acknowledgements}

This paper is part of Hee Jin Kim's thesis for 2019 Master's degree.

\section{Conflicts of Interest}

The authors declare no conflicts of interest regarding the publication of this paper.

\section{References}

Ahn, J. A., Yea, C. J., \& Yeum, D. M. (2011). The Impact of Nurses' Job Demands, Job Resources, Emotional Labor and Emotional Intelligence on Burnout. Social Science Research Review, 27, 25-43.

Ashforth, B. E., \& Humphrey, R. (1993). Emotional Labor in Service Roles: The Influence of Identity. Academy of Management Review, 18, 88-115. https://doi.org/10.5465/amr.1993.3997508

Brotheridge, C. M. (2001). A Comparison of Alternative Models of Coping: Identifying Relationships among Coworker Support, Workload, and Emotional Exhaustion in the Workplace. International Journal of Stress Management, 8, 1-14. https://doi.org/10.1023/A:1009551028558

Cherniss, C. (1980). Professional Burnout in the Human Services Organizations. New York: Praeger Publishers.

Collins, S., \& Long, A. (2003). Working with Psychological Effects of Trauma: Consequences for Mental Healthcare Workers-A Literature Review. Journal of Psychiatric and Mental Health Nursing, 10, 417-424. https://doi.org/10.1046/j.1365-2850.2003.00620.x

Conrad, D., \& Kellar-Guenther, Y. (2006) Compassion Fatigue, Burnout, and Compassion Satisfaction among Colorado Child Protection Worker. Child Abuse \& Neglect, 30, 1071-1080. https://doi.org/10.1016/j.chiabu.2006.03.009

Delia, C., \& Patrick, T. (1996). Stress in Clinical Psychologist. The International Journal of Social Psychiatry, 42, 141-149. https://doi.org/10.1177/002076409604200208

Dormann, C., \& Kaiser, D. M. (2002). Job Conditions and Customer Satisfaction. European Journal of Work and Organizational Psychology, 11, 257-283.

https://doi.org/10.1080/13594320244000166 
Fetter, K. L. (2012). We Grieve Too: One Inpatient Oncology Unit's Interventions for Recognizing and Combating Compassion Fatigue. Clinical Journal of Oncology Nursing, 16, 559-561. https://doi.org/10.1188/12.CJON.559-561

Figley, C. R. (2012). Treating Compassion Fatigue. New York: Brunner-Routledge. https://doi.org/10.4324/9780203890318

Figley, C. R., \& Stamm, B. H. (1996). Psychometric Review of Compassion Fatigue SelfTest. In B. H. Stamm (Ed.), Measurement of Stress, Trauma, and Adaptation (pp. 127 130). Lutherville, MD: Sidran Press.

Friedman, R. (2002). The Importance of Helping the Helper. Trauma and Child Welfare. New York: Basic Books.

Heuven, E., \& Bakker, A. (2003). Emotional Dissonance and Burnout among Cabin Attendants. European Journal of Work and Organizational Psychology, 12, 81-100. https://doi.org/10.1080/13594320344000039

Hong, S. H. (2000). The Criteria for Selecting Appropriate Fit Indices in Structural Equation Modeling and Their Rationales. Korean Journal of Clinical Psychology, 19, 161-177.

Jeon, S. Y., \& Ha, J. Y. (2012). Traumatic Event, Professional Quality of Life and Physical Symptoms among Emergency Nurses. Korean Journal of Adult Nurses, 24, 64-73. https://doi.org/10.7475/kjan.2012.24.1.64

Jeong, H. L. (2016). Effects of Emergency Department Nurses' Emotional Labor on Professional Quality of Life: Focusing on Mediating Effects of Emotional Dissonance. Unpublished Master's Thesis, Daegu: Keimyung University.

https://doi.org/10.5762/KAIS.2016.17.11.491

Jun, Y. J. (2013). Affect among Traumatic Events, Compassion Fatigue, Self-Esteem, Compassion Satisfaction and Burnout of Nurses in Emergency Department. Unpublished Master's Thesis, Gimhae: Inje University.

Kim, H. J. (2011). The Relationships between Traumatic Events, Compassion Fatigue, Burnout and Compassion Satisfaction in Emergency Nurses. Unpublished Master's Thesis, Seoul: Konkuk University.

Kim, H. J., \& Kim, J. H. (2013). Development and Validation of the Competency Scale for Call Center Consultants. Korean Journal of Counseling, 14, 2833-2850. https://doi.org/10.15703/kjc.14.5.201310.2833

Kim, J. E. (2013). Hardiness, Compassion Fatigue, Compassion Satisfaction and Burnout among Geriatric Hospital Nurses. Unpublished Master's Thesis, Seoul: Chung-Ang University.

Kim, J. H. (1987). Relations of Perceived Stress, Cognitive Set, and Coping Behaviors to Depression. Unpublished Doctoral Dissertation, Seoul: Seoul National University.

Kim, R. B. (2019). The Relationship of Risk Factors in Job Environment and Burnout Firefighters: The Moderating Effect of Compassion Fatigue. Unpublished Master's Thesis, Seoul: Hanyang University.

Kim, S. J. (2014). The Mediating Effect of Job Stress and Social Support on the Relationship between Physical Therapists' Self-Resilience and Burnout. Unpublished Doctoral Dissertation, Cheonan: University of Brain Education.

Kirk, S. A., Koeske, G. F., \& Koeske, R. D. (1993). Changes in Health and Job Attitudes of Case Managers Providing Intensive Services. Hospital and Community Psychiatry, 44, 168-173. https://doi.org/10.1176/ps.44.2.168

Korea Health Industry Development Institute (2005). Utilization of Private Health Resource Participation to Expand Private Rehabilitation Service. Seoul: Korea Health Industry Development Institute. 
Kruml, S. M., \& Geddes, D. (2000). Exploring the Dimensions of Emotional Labor: The Heart of Hochschild's Work. Management Communication Quarterly, 14, 8-49. https://doi.org/10.1177/0893318900141002

Lee, H. K., \& Jung, J. Y. (2016). Factors of Job Stress Influencing Burnout and Compassion Satisfaction in Occupational Therapist. Journal of Special Education \& Rehabilitation Science, 55, 233-245. https://doi.org/10.15870/jsers.2016.03.55.1.233

Lee, H. S. (2015). Effect on Spiritual Well-Being, Compassion Fatigue and Compassion Satisfaction on Burnout among Nurses Working in Oncology Unit. Unpublished Master's Thesis, Busan: Kosin University.

Lee, J. M., \& Yom, Y. H. (2013). Effect of Work Stress, Compassion Fatigue, and Compassion Satisfaction on Burnout in Clinical Nurses. Journal of Korean Academy of Nursing Administration, 19, 689-697. https://doi.org/10.11111/jkana.2013.19.5.689

Lee, N. H. (2011). A Study on the Relationship between Burnout, Job Stress and Self-Efficacy in Psychiatric Nurses. Unpublished Master's Thesis, Seoul: Ewha Woman's University.

Lewig, K. A., \& Dollard, M. F. (2003). Emotional Dissonance, Emotional Exhaustion and Job Satisfaction in Call Centre Workers. European Journal of Work and Organizational Psychology, 12, 355-392. https://doi.org/10.1080/13594320344000200

Lloyd, C., \& King, R. (2001). Work-Related Stress and Occupational Therapy. Occupational Therapy International, 8, 227-243. https://doi.org/10.1002/oti.148

Lombardo, B., \& Eyle, C. (2011). Compassion Fatigue: A Nurse's Primer. The Online Journal of Issues in Nursing, 16, 3.

Mann, S. (2004). People-Work: Emotion Management, Stress and Coping. British Journal of Guidance \& Counselling, 32, 205-221. https://doi.org/10.1080/0369880410001692247

Maslach, C., \& Jackson, S. E. (1981). MBI: Maslach Burnout Inventory. Palo Alto, CA: University of California, Consulting Psychologists Press. https://doi.org/10.1037/t05190-000

Morris, J. A., \& Feldman, D. C. (1996). The Impact of Emotional Dissonance on Psychological Well-Being: The Importance of Role Importance of Role Internalization as a Mediating Variable. Management Research News, 19, 19-28. https://doi.org/10.1108/eb028484

Park, S. E. (2008). An Empirical Study on the Relationships among Employees' Perceived Display Rule Demands, Emotional Dissonance, and Their Psychological Responses. Journal of Organization and Management, 32, 25-53.

Park, S. E., \& Shin, D. H. (2011). Emotional Labor and Work-Family Conflict as Two Antecedents to the Job Burnout. Korean Journal of Management, 19, 227-266.

Preacher, K. J., \& Hayes, A. F. (2008). Asymptotic and Resampling Strategies for Assessing and Comparing Indirect Effects in Multiple Mediator Models. Behavior Research Methods, 40, 879-891. https://doi.org/10.3758/BRM.40.3.879

Robertson, S., \& Gow, K. M. (2011). How Burned Out Employees Perceive Work Stress and Organizational Burnout. In Wayfinding through Life's Challenges: Coping and Survival (pp. 385-402). Hauppauge, NY: Nova Science Publishers.

Robins, P. M., Meltzer, L., \& Zelikovsky, N. (2009). The Experience of Secondary Traumatic Stress upon Care Providers Working within a Children's Hospital. Journal of Pediatric Nursing, 24, 270-279. https://doi.org/10.1016/j.pedn.2008.03.007

Sabo, B. M. (2008). Adverse Psychosocial Consequences: Compassion Fatigue, Burnout and Vicarious Traumatization: Are Nurses Who Provide Palliative and Hematological 
Cancer Care Vulnerable? Indian Journal of Palliative Care, 14, 23-29. https://doi.org/10.4103/0973-1075.41929

Seffrin, B. A. (2002). Emotional Labor in Care Giving Organizations. Unpublished Doctoral Dissertation, Columbus, OH: The Ohio State University.

Seo, J. H. (2012). Influences of Emotional Intelligence of Psychotherapist in Rehabilitation Domain upon Psychological Burnout. Unpublished Doctoral Thesis, Kyungsan: Daegu University.

Shin, M. J. (2007). Compassion Fatigue, Burnout, and Compassion Satisfaction among Child Protection Agency Workers in Korea. Unpublished Master's Thesis, Seoul: Sookmyung Woman's University.

Slocum-Gori, S. (2011). Understanding Compassion Satisfaction, Compassion Fatigue and Burnout: A Survey of the Hospice Palliative Care Workforce. Palliative Medicine, 27, 172-178. https://doi.org/10.1177/0269216311431311

Stamm, B. H. (2002). Measuring Compassion Satisfaction as Well as Fatigue: Developmental History of the Compassion Satisfaction and Fatigue Test. Psychosocial Stress Series, 24, 107-119.

Stamm, B. H. (2009). Professional Quality of Life: Compassion Satisfaction and Fatigue Version 5 (ProQOL). http://www.proqol.org

Stamm, B. H. (2010). The Concise ProQOL Manual (2nd ed., pp. 8-30). Pocatello, ID: The ProQOL.

Suh, M. S., \& Kim, S. H. (2002). A Study on the Influencing and Moderating Factors of Service Provider's Emotional Dissonance in the Service Encounter. Korean Marketing Association, 20, 111-145.

Woo, J. P. (2012). Understanding of Structural Equation Modeling and Its Concepts. Seoul: Hannarae Publisher.

Yang, H. S. (2013). Effects of Work Stress, Compassion Fatigue and Compassion Satisfaction on Burnout in Operating Room Nurses. Unpublished Master's Thesis, Seoul: ChungAng University.

Yom, Y. H., \& Kim, H. J. (2012). Effect of Compassion Satisfaction and Social Support in the Relationship between Compassion Fatigue and Burnout in Hospital Nurses. Journal of Korean Academy of Nursing, 42, 870-878. https://doi.org/10.4040/jkan.2012.42.6.870

Yoo, S. K., \& Park, S. H. (2002). Influence of Occupational Stress and Perceived Social Support on Counselors' Burnout in Korea. The Korean Journal of Counseling and Psychotherapy, 14, 389-400.

Yoon, K. S. (2003). A Study on the Job Stress and Coping of Emergency Nurses. Unpublished Master's Thesis, Seoul: Chung-Ang University. 